\title{
LA FIJACIÓN DE SENTIDOS TERRITORIALES EN UNA FRONTERA EN MOVIMIENTO
}

\author{
The Identity Politics of Memories and Belonging in a Dynamic Frontier \\ Rosa Torras-Conangla
}

Resumen: A partir de la comparación entre dos oleadas de migrantes llegados en momentos y circunstancias diversos a la cuenca del río Candelaria, estado de Campeche, en el artículo se propone un acercamiento a cómo se construyen los sentidos de pertenencia territorial en espacios de frontera cuya dinámica de poblamiento se define por la constante movilidad. Las distintas modalidades de colonización, y sobre todo el apoyo gubernamental diferenciado, han creado disputas por la memoria de los orígenes entre los actuales pobladores de esa zona fronteriza, abonadas por las políticas estatales mexicanas dirigidas a activar memorias fuertes que consoliden su hegemonía sobre sus extremos territoriales y frente al vecino país de Guatemala.

Palabras clave: colonización, fronteras, migraciones, memorias, territorialidad.

Abstract: By comparing two waves of migrants that arrived, in distinct moments and under different circumstances, to an area delimited by the basin of the Candelaria River in Campeche, this article strives to explain how a sense of belonging is constructed in borderlands where the dynamic of the population is defined by constant mobility. The distinct variants of colonization, and above all the presence of unequal governmental support, has created disputes for the memory of origin among the current population of this frontier zone, enhanced by the Mexican state's initiatives to activate memories that consolidate their hegemony over the furthest limits of their territory and in opposition to the neighboring country of Guatemala.

Keywords: colonization, borderlands, migration, construction of memory, territoriality.

Rosa Torras Conangla, doctora en Estudios Mesoamericanos de la Universidad Nacional Autónoma de México. Investigadora del Centro Peninsular en Humanidades y en Ciencias Sociales de la Universidad Nacional Autónoma de México (CEPHCIS-UNAM). Temas de especialización: historia agraria del sur de Campeche, territorialidad, frontera, memoria e historia. Correo electrónico: mima638@gmail.com.
Enviado a dictamen: 27 de octubre de 2015. Aprobación: 29 de enero de 2016. Revisiones: 1 . 


\section{Introducción}

$\longrightarrow$ on el presente artículo se pretende abonar a la reflexión sobre las paradojas del largo proceso de construcción de las fronteras en el sureste mexicano, poniendo en diálogo las nociones de colonización y colonialismo, así como de frontera frente y frontera límite, desde el actual municipio de Candelaria en el sur del estado de Campeche, fronterizo con El Petén guatemalteco. Éste es un espacio marcado por el impulso gubernamental de proyectos económicos extractivos, con una histórica movilidad de asentamientos humanos en condiciones de vida precarias, y vital geoestratégicamente por estar situado en el límite con Guatemala. Con una mirada histórica sobre los distintos ciclos de colonización vividos en la región, el acercamiento a cómo hoy día sus habitantes expresan sus sentidos de pertenencia territorial permite indagar en las formas en que el Estado mexicano ha tratado de consolidar su hegemonía en sus extremos más periféricos.

Sucesivas oleadas de colonos, siempre expresión de circuitos de migración interna, han ido conformando el imaginario territorial de los pobladores que habitan hoy día Candelaria no sin conflicto, con un eje conductor que se debate entre el afán por pertenecer a un espacio determinado - es decir, territorializar-y las contradicciones inherentes a los permanentes flujos de población llegados a merced de lógicas económicas nacionales y globalizadas. Estamos, entonces, en un ámbito selvático y de frente pionero, con una clara historia de asentamientos inestables y de continuas oleadas migratorias al vaivén de los distintos ciclos de colonización impulsados por un Estado en construcción de su propia legitimidad territorial.

Jean Revel-Mouroz, en su estudio sobre la colonización del trópico húmedo mexicano, concluye que la explotación forestal de carácter predatorio no coloniza, si entendemos la colonización como "la que pueblay desarrolla", pues genera poblamientos inestables con economías subalternas dependientes del exterior (Revel-Mouroz, 1980: 13, 316). No obstante, como bien señalan Ramón González Ponciano y Andrés Fábregas
Puig (2014: 10-11), para comprender las políticas de colonización de la selva en el sur mexicano debemos tomar en cuenta los intereses de ese Estado-nación en nacionalizar su frontera internacional con Guatemala.

Por ello, cabe preguntarse: icómo entender de qué manera se conjugan - o confrontan - las necesidades gubernamentales de fijar un territorio de frontera ante Guatemala con una realidad de sociedad en movimiento, cuya base productiva - maderera, comercial, con larga trayectoria de regímenes de propiedad latifundistas y uso de mano de obra temporal - no ha propiciado asentamientos históricamente duraderos que permitan la apropiación territorial? ¿Cómo el Estado mexicano ha construido su legitimidad en ese extremo visto como "salvaje", "aislado" y "díscolo" por haber sido una zona de refugio de contrabandistas, mayas rebeldes y cimarrones? ¿Cómo mexicanizar en la subalternidad?

A partir del contraste entre fuentes orales y de archivo - sobre todo judiciales-, lugares de memoria y relatos publicados por los mismos pobladores, intento incursionar por los senderos de la memoria territorial en el desarraigo, por la construcción de identidades asociadas con un territorio en permanente disputa, tanto de recursos como de referentes culturales, en diálogo con las políticas gubernamentales de mexicanización de la frontera — de incorporación espacial, ideológica y cultural- y con las prácticas colonizadoras de los agentes privados.

Para ello, quisiera distinguir dos momentos en el proceso mencionado de territorialización de Candelaria:

- Uno vinculado a la explotación maderera para la exportación, que tuvo lugar durante el siglo XIX y la primera mitad del XX, que incluyó la definición del límite con Guatemala. La explotación se inició con el corte de palo de tinte controlado por las élites de Ciudad del Carmen - Campeche- las que, una vez agotado el negocio, empezaron con la extracción de chicle, que rápidamente traspasaron a compañías estadounidenses.

- Otro, marcado por la memoria gubernamental como "la colonización", tuvo lugar durante la década de 1960. Este ciclo arrancó con el 
Programa de Colonización establecido por el presidente López Mateos en 1962, mediante el cual se creaban Nuevos Centros de Población Ejidal. El gobernador campechano de esos tiempos, el coronel Ortiz Ávila, organizó la llegada de campesinos sin tierra de otros estados de la Federación para establecer colonias en las selvas del sur de Campeche. Candelaria fue la zona más favorecida con la llegada de colonos en 1963 procedentes de Torreón, en el estado de Coahuila (Sierra, 1998: 196; Fábregas, 2012: 12).

\section{La colonización "modernizante": expansión maderera}

$\mathrm{Al}$ reconstruir las formas de tenencia de la tierra en la zona a partir de la legislación liberal de denuncios de baldíos (Ley de 1863), vemos de forma clara cómo el Estado mexicano facilitó la apropiación particular de grandes extensiones de tierra para la explotación de sus recursos forestales a las élites carmelitas, con el compromiso de poblarlas con mexicanos bajo un régimen de explotación laboral al que quedaban sujetos los pobladores que sí vivían en ellas - a menudo sin propiedad regularizada-; era una población fundamentalmente indígena — chontal y maya yucateca- y afrodescendiente o parda. ${ }^{2}$

Un caso paradigmático de ese proceso de colonización es el de Ana Niévez de Repetto, quien en 1892 — en pleno periodo de delimitación de la frontera entre Guatemala y México — ${ }^{3}$ adquirió enormes cantidades de tierra alrededor de su finca San Pedro, al acogerse a la ley de 1883 mediante la cual el Gobierno mexicano entregaba grandes extensiones de tierra a compañías deslindadoras. Ana Niévez — reconocida legalmente con el carácter de empresa deslindadora de baldíos- firmó un contrato con la Secretaría de Fomento en concepto de compra-venta y colonización de las tierras baldías mencionadas, que comprendían una extensión limitada por el estado de Tabasco, el río Candelaria y la República de Guatemala. El ingeniero encargado de hacer la medición describía esas tierras como ricas en palo de tinte, en árboles de chicozapote y en maderas preciosas, mientras argumentaba:

Queriendo la Señora [Niévez de] Repetto obtener de la Nación una gran superficie, dispuso que dejando dentro de ella los Ranchos de San Pedro y Pejelagarto, se midiera una gran extensión que tuviera linderos perfectamente claros y permanentes eligiendo por límites la línea limítrofe de Guatemala, la conocida con el nombre de Tabasco y el río Pakaytún. ${ }^{4}$

El mapa 1 muestra la extensión de la finca San Pedro y Anexo" y su ubicación, como resultado del contrato mencionado.

A razón de cuatro pesos por hectárea para las tres cuartas partes del terreno, y por cesión gratuita la tercera parte restante, doña Ana quedó como única dueña de una superficie de 44094 hectáreas, ${ }^{5}$ con la obligación de establecer un colono por cada 2500 hectáreas, colonos que debían ser de nacionalidad mexicana aprobada por el Gobierno, sin ningún derecho de extranjería. La empresa debía ser, asimismo, mexicana y quedaría roto el contrato si doña Ana no cumplía con la obligación de establecer colonos y si no iniciaba operaciones de deslinde dentro del plazo improrrogable de tres meses, así como si traspasaba, enajenaba o hipotecaba sus derechos a algún gobierno extranjero o si lo admitía como socio. Por último, si no "colocaba" los colonos acordados, debía pagar una multa de cincuenta pesos por cada uno que faltara. El contrato se firmó el 2 de diciembre de 1893 y en la medición quedó constancia de que se trataba de los mismos terrenos que habían sido solicitados en 1892, cuyo límite se asentaba sobre la conocida como "línea de Guatemala", marcada por los ingenieros de la Comisión de Límites de México. Con ello, la línea de separación entre los dos Estados, fijada pocos meses antes como producto de un complejo proceso diplomático, fue, como detallaremos a continuación, definitivamente establecida por la territorialización a través de la colonización privada.

Ana Niévez de Repetto —nacida en 1846 en la actualmente llamada Ciudad del Carmen- ${ }^{6}$ fue la principal heredera de su padre Victoriano Niévez 
Céspedes, la mayor fortuna carmelita de la época, fortuna construida a partir de sus actividades en el comercio, el transporte, la producción y el ejercicio de prestamista. Antes que ella, habían sido propietarios de la finca San Pedro su suegro Juan Repetto Simonet, Marcelo Mucel y Enrique Pauling, todos avecindados en Ciudad del Carmen, migrantes o hijos de migrantes europeos o estadounidenses, integrados a la élite regional gracias al capital social que suponía su origen en un México en pleno proceso de colonización "blanqueadora" fomentada por los liberales positivistas, lo que les permitió insertarse en la élite local y regional y hacer rendir sus habilidades empresariales.

Los colonos extranjeros llegados de forma individual contribuyeron de forma decisiva a la expansión de las fronteras internas de un México que se estaba construyendo como nación. Su aporte fundamental era el blanqueamiento de la misma élite regional, al ser ésta una estructura caciquil de rancheros criollo-mestizos, que se movía entre una mayoría de población indígena - chontal y maya yucateca - y parda que habitaban la región desde épocas prehispánicas y coloniales, un proceso que arrancó en tiempos del palo de tinte y se consolidó durante la bonanza chiclera a lo largo de todo el siglo XIX y la primera mitad del XX. Así, el avance de la frontera, impulsado desde Ciudad del Carmen —en pleno Golfo de México- por toda la cuenca del río Candelaria, se fue desarrollando tierra adentro en busca del Petén mítico, a donde la llevaba el mismo río por ser su lugar de nacimiento (Torras, 2013).

El proceso de construcción territorial del México republicano en su extremo sureste no fue nada sencillo. Aspiraciones "independentistas" de carmelitas, años de disputa separatista de la región histórica yucateca hasta su reincorporación definitiva en 1850, más la Guerra de castas, dieron como resultado la fractura administrativa de la Península de Yucatán con la creación del estado de Campeche en 1863 y del territorio de Quintana Roo en 1904, lo que garantizó su integración definitiva a la República mexicana. Fueron juegos entre élites, siempre emparentadas y con comportamientos y características más que similares, cuya defensa de sus intereses expresados territorialmente los llevó a enfrentamientos y reacomodos continuos. Y fue precisamente en los ricos bosques madereros codiciados por la creciente élite carmelita, que conectaban por vía terrestre la península con el resto de México, donde se concentró la disputa territorial a menudo expresada en el ámbito jurisdiccional.

No obstante, ni los Mucel ni los Repetto o los Pauling actuaban fuera de contexto, pues el impulso a la modalidad de colonización esbozada era ideario fundamental en el México decimonónico. Los valores necesarios para alcanzar el anhelado progreso liberal sólo podían adquirirse consolidando a las élites locales y regionales a partir de la llegada escalonada de hombres - pocas mujeres - de origen europeo o norteamericano con notables anhelos de integración, cuyo mayor capital sería su origen blanco, dispuestos a territorializar bajo los atributos propios de la tan deseada modernidad, es decir, a controlar tanto sus recursos naturales, como la población local, aliándose con quienes les facilitaran el proceso y, al mismo tiempo, gozando de las posibilidades de ascenso social que esta dinámica ofrecía: pasar de formar parte de una élite local a una de ámbito regional, integrada "armónicamente" a la nacional.

La mayoría de los grandes propietarios, primero carmelitas y luego estadounidenses, de las tierras candelarienses que a lo largo de todo el siglo XIX y de la primera mitad del XX explotaron sus bosques residían en Ciudad del Carmen o en el extranjero, por lo que Candelaria se fue habitando con una población compuesta por migrantes chicleros, pequeños comerciantes, jornaleros sin tierras o trabajadores ferroviarios que llegaron con la construcción del Ferrocarril del Sureste, inaugurado finalmente en 1950. Fueron ellos quienes, en 1939, solicitaron dotación de tierras para fundar el pueblo de Candelaria. ${ }^{7}$

La modalidad de constitución territorial que encontramos en la región de Candelaria es la misma que presentan la mayoría de áreas selváticas de América Latina, consideradas por los Estados republicanos dentro de la racionalidad del extractivismo: ciclos continuados de migración-colonización-conflictomigración, que se sobreponen siempre bajo la lógica 
de espacio "vacío" y de un territorio "ausente". Vacío en términos culturales y poblacionales, pero sobre todo en términos de legalidad reconocida en cuanto a la propiedad de la tierra de quienes, innegablemente, vivían allí. Ausente porque, en el proceso de construcción de los Estados-nación, éstas son consideradas como áreas periféricas que hay que incorporar a la dinámica civilizatoria, al imaginario nacional.

Estamos, pues, ante un claro ejemplo de la clásica tesis ampliamente difundida por Frederick Jackson Turner sobre la frontera, entendida como "frente de expansión" de pioneros a quienes el Estado les ofreció tierras supuestamente deshabitadas y "salvajes", que explotaron gracias a su esfuerzo individual (Turner, 1987).

Pero si esa era la ideología territorial que se desprende de las fuentes documentales decimonónicas -marcadamente oficiales - iqué hay de ella en las memorias actuales de quienes habitan ese espacio?

Con esa primera fase de reconstrucción documental, me fui a la zona de Candelaria esperando encontrar un imaginario territorial oficial asociado con la explotación chiclera, pero no fue así. Veamos.

La colonización "mexicanizante": disputas por la memoria en tierras de frontera

Aquí en Candelaria hay tres sociedades: los naturales, los colonos y, digamos, los de importación. Primero los naturales de aquí, de Candelaria, entre ellos estoy yo y un montón de amigos de acá que vimos crecer este pueblo. Nuestros padres fueron los fundadores. Luego hay otros que son los colonos, los norteños. La mayoría ya nació aquí en Candelaria, son hijos de colonos, pero se sienten muy orgullosos de su descendencia del norte de la República. No se sienten candelarienses. Y últimamente ya nos invadieron los de Guerrero y los michoacanos [...] Esa es la división que tenemos aquí en Candelaria. [...] El problema es la forma de conducirse de ellos, es que se sienten muy orgullosos de no ser de acá. Y la culpa es del gobierno, que sigue tratando a los colonos como norteños, no como campechanos (entrevista personal, Candelaria, 2015)
Con esas sentidas palabras describe "el problema de Candelaria" un poblador del municipio. Hijo de un español que llegó a esas tierras selváticas como empleado de tienda en los tiempos del auge de la extracción de chicle en las primeras décadas del siglo XX, él y sus paisanos se muestran indignados por las recientes acciones gubernamentales destinadas a fijar en la memoria local el papel de "los colonos" de la década de 1960 como los fundadores del pueblo. "Que digan que la fundadora de Candelaria sea una señora colona, siendo que cuando ellos llegaron ya tenía veinticinco años de haberse fundado Candelaria... ipues que vayan a engañar a otras personas, no a nosotros que estamos aquí!", sigue lamentándose haciendo mención a la participación de una colona presentada como fundadora de Candelaria en el acto oficial que tuvo lugar en mayo de 2014 durante el cual el gobernador de Campeche, junto con el de Coahuila, anunciaron la construcción del Museo de la Colonización e inauguraron la estatua del coahuilense impulsor del Programa de Colonización oficial de 1963. Un año antes, los mismos gobernadores habían develado una placa en el parque central del pueblo de Candelaria, en la que quedaba asentado que con dicho Programa llegaron los primeros colonos al sur de Campeche, cuando los que fueron chicleros llevan años reivindicando un monumento recordatorio del médico que los atendía en los estragos de su vida en la selva.

Placas en el parque central, museos, estatuas, una cancha de fútbol bautizada "Los Colonizadores". ¿Por qué esa insistencia gubernamental en imprimir el evento de la colonización de 1963 en el espacio público y fijar una versión histórica sobre la "fundación" de la localidad que implica el olvido de su pasado reciente y vívido como asentamiento neurálgico durante la época chiclera?

Al estirar el hilo de la memoria territorial, empecé a atisbar el contraste entre las políticas colonizadoras y la vivencia migratoria centrada en la disputa contra la voluntad gubernamental de fijar la memoria sobre quiénes fueron los "primeros colonos", voluntad que desplaza la experiencia chiclera en favor de los proyectos colonizadores oficiales de la década de 1960. Agotado el ciclo productivo del chicle, basado en la atracción de fuerza laboral temporal llegada de otros 
puntos de la región, el Gobierno mexicano impulsó un nuevo ciclo de colonización en este territorio selvático por medio de población del norte de la República, sobre todo de Coahuila. Inicialmente fueron quinientas familias campesinas coahuilenses, a las que luego se añadieron otras de todos lados de la República; todos ellas pasaron a ser "los norteños" y "los colonos". De esta manera lo recuerda una colona: "Mi papá me llevó a varias partes para visitar a gente que le decíamos 'nativa', personas que ya se encontraban aquí desde tiempo atrás". Por su parte, otro colono aseveraba: "Los nativos se consideraban dueños de la selva, la mayoría eran campechanos y tabasqueños; decían que nosotros veníamos a expropiar, nos nombraban norteños".

Hoy día, las familias más “antiguas” de la región de Candelaria llevan viviendo en el área tres generaciones. Sus padres y abuelos llegaron en los tiempos de la explotación maderera desde otros puntos de la región $y$, poco a poco, se fueron quedando. Al entrevistar a ancianos que habían dedicado su vida al chicle, así como a sus hijos y nietos, vemos que emerge la fuerte disputa con la oleada migratoria que les sucedió unas décadas después. Tras contar la dura experiencia de vida de su abuelo, un tamaulipeco que llegó a Candelaria a trabajar en la chiclería a inicios del siglo XX, un candelariense manifestaba la ofensa colectiva por la placa dedicada a "los norteños" en el centro del pueblo:

Usted puede encontrar en Candelaria [gente] sin excepción de todos los estados de la República. Pero eso no comenzó como nos quieren hacer creer los parámetros gobernistas [sic], eso no comenzó hace cincuenta años con la llegada de los norteños. De antes eran oleadas y oleadas de gente que venían de fuera. Por eso, si usted me pregunta, no estoy de acuerdo con esta placa que hay en el parque. Y quieren venderle la idea a todo el mundo que viene a Candelaria o que conoce algo de la historia de Candelaria, de que gracias a esa gente que vino del norte [...], Candelaria empezó a crecer y progresar. Más del cincuenta por ciento de esa gente que un día trajeron del desierto a Candelaria, donde todo era abundancia, se regresó a su tierra porque no estaba acostumbrada a trabajar. Estaba acostumbrada a que la mantuviera el gobierno. Y la siguieron manteniendo. Todos trabajaban para ellos porque eran planes del gobierno. Los planes del gobierno sólo eran para ellos, para los colonos. Mire, todos los lugares donde se establecieron los colonos, en todos esos lugares había gente viviendo. Y todos los lugares tenían otros nombres porque había gente viviendo. Por ejemplo, aquí, en Venustiano Carranza, no se llamaba Venustiano Carranza, se llamaba La Lucha. Y fue también un centro chiclero. Simplemente dijeron: "tú ya no puedes estar aquí". Y allí vivía gente cuando empezaron a llegar los del norte. Y a la gente que tenía ya muchos años de estar viviendo ahí le dijeron: "salte porque esto ya no te pertenece". Era gente que vivía ahí pero no tenía papeles, pero tenía años de años viviendo ahí. Contra el gobierno... Ya sabe, gente pobre. Ahora, yo no digo que ellos [los norteños] no tengan un valor dentro de la historia de Candelaria. Por supuesto que lo tienen, pero no es el valor que le dan. A ellos les trajeron maestros, a ellos les trajeron médicos, todo; a ellos les pusieron agua potable (entrevista personal, Candelaria, 2013).

Pero, ¿cuál es la visión de "los colonos", de "los norteños"? Así lo cuenta un michoacano cuyo padre se unió al Programa de Colonización de 1963 junto con toda su familia:

En el 63 todo esto era montaña, todos estos lugares eran centros chicleros. No recuerdo de quién era propiedad. Son terrenos nacionales. Ahí había asentamientos de un señor que se llamó Pastor Piedra, otro de Agustín Zavala, otro terreno del doctor Vargas; eran terrenos que habían posesionado, pero no habían denunciado esas tierras ante el agrario. Cuando se abre la colonización, esas tierras las toma el gobierno y las dona. Uno nada más se quedó. Los demás se fueron, decidieron mejor abandonar las tierras. Por dignidad, por orgullo, por vergüenza, por coraje, por lo que haya sido, se retiraron (entrevista personal, Candelaria, 2015) 
El proceso descrito es muy parecido al vivido en el siglo XIX: es el acceso a títulos sobre las tierras lo que otorga legitimidad a un grupo o individuo sobre otros, independientemente de si las mismas ya estaban ocupadas o no. Esta legitimidad se impuso, también, simbólicamente, como expresa otro colono:

Todos habitábamos en lugares donde no había tierra, y donde había la promesa de que acá había en abundancia, pues era el objetivo. Sentirnos dueños y posesionarnos de una tierra que no era nuestra. Donde sucediera lo mismo que nuestros abuelos, las generaciones anteriores, la tierra ahí estaba, siendo herencia para los que quedaban. Algo parecido era el interés común.

Hubo algunos roces, porque a veces la gente que viene del interior resulta hasta cierto punto arrogante, no me cansa decirlo, no debería de decirlo, pero es la verdad. No me ha sucedido a mí, pero lo vi en los mayores que en ese momento andaban por acá. Sintiéndose que venían de un lugar más civilizado, con una cultura mayor. Y llegar a un lugar pobre, un tanto primitivo, pues había una especie de diferencia. Considerar que la gente que vive acá estaba en desventaja de muchas cosas, cuando en realidad no fue así. Porque aunque allá se tenían algunas ventajas, vinimos a aprender lo que no sabíamos. Lo que la gente campechana natural de acá es una gente muy linda, nos enseñaron, y que adoptamos. No porque lo veíamos correcto o porque era lo mejor, o porque estaba en mejor posición de imponer su cultura, sino porque, en la región, por fuerza mayor había que adaptarse. Ellos eran sabios aquí. Eran personas que conocían el comportamiento de la selva. De cada ruido. La posición de las nubes, cosas así. Cuando empezaron a sentir la presencia de gente de otros lugares y empezaron a sentir su forma de ser, ellos empezaron a sentir la presión y uno a uno empezó a retirarse, al extremo que se quedaron los fundadores que vinieron de otro lado, que fuimos nosotros, porque nosotros sí nos adaptamos a esa forma. Estábamos dentro de esa forma. Hasta la fecha ahí vivimos. Pero el campechano, aunque no decía nada, lo que él decía era con mucho cuidado, eran muy prudentes. Se fueron retirando a lugares donde ellos se sentían a gusto, donde hubiera más gente de ellos, o sea, campechanos. No había mucha compatibilidad. Sí hubo y hay relación, pero ellos son de los que les gusta estar a distancia. Con el tiempo, los hijos, nosotros, hemos roto esa separación, no solamente con los campechanos, con los tabasqueños, con los chiapanecos, con los veracruzanos, con los guanajuatenses, con los de Torreón, con Jalisco... A mí me gustaría que esa inscripción [la placa en el parque] tuviera otras palabras que resaltaran a los campechanos. Le dieron asilo y albergue a la gente que venía del interior. Que se resalte que en verdad esta gente nos recibió bien, nos trata bien, vivimos bien. Yo campechano, yo hijo purépecha, y que mucho me gustaría hablar mi lengua (entrevista personal, Candelaria, 2015).

Al igual que en Chiapas, la promesa de recibir tierras en propiedad, luego incumplida, fomentó la llegada a la frontera de campesinos desde otras regiones mexicanas a terrenos supuestamente nacionales a menudo reivindicados por los pobladores que ya las habitaban (Del Carpio, 2004).

Con la llegada de "los norteños", los chicleros - también migrantes y muchos de ellos también norteños - pasaron a ser "los nativos" y así se consideran ellos mismos; no obstante, las particularidades de su inserción en las tierras de la selva, provocadas sobre todo por las políticas gubernamentales, han roto el estatuto de homogeneidad pretendido. Viven como grupos opuestos, enfrentados por el apoyo gubernamental diferenciado, por haber recibido o no ayuda gubernamental en el momento de su llegada a Candelaria o por ser parte o no de la memoria oficial del estado y del municipio.

Los lugares de memoria erigidos recientemente fijan en el espacio público una versión histórica, que ya había sido ampliamente difundida en documentales, fotografías y relatos testimoniales que durante 
cincuenta años han oficializado la idea fundacional de esa gesta colonizadora de "los norteños" cual imaginario decimonónico: "el asalto a las tierras vírgenes, colonizar, descubrir y explotar nuestras riquezas abandonadas". Idea de espacio vacío que contrasta con los testimonios que documentan que allí sí vivía gente antes de su llegada.

Un ejemplo es la publicación — aparecida en el año 2009- del libro titulado Chan-colona. Imagen del pasado, orgullodel presente, texto escrito y publicado por Maritoña Quiriarte Rodríguez, quien en sus propias palabras se define como "chan-colona": "nombre que doy a los hijos de colonos que como yo, nacimos o crecimos en Campeche", puesto que "chan" es una palabra maya utilizada coloquialmente como sinónimo de "a medias". Doña Maritoña afirma: "Los chan-colonos aprendimos a amar las letras del Himno Campechano y, aunque no somos hijos de marinos y nuestros antepasados tampoco son de linaje maya [imaginario oficial del campechano popular], nos jactamos en decir que somos campechanos" (Quiriarte, 2009: 7 y 21).

Con una clara intención de reivindicar su pertenencia territorial, la autora narra la experiencia del Programa de Colonización destinado a "poblar las márgenes del Río Candelaria con 700 familias del Norte del país, que emprendieron el éxodo al Sur de Campeche con la promesa de que tendrían suficientes tierras". Como ya se indicó, fueron menos familias, todas de la Comarca Lagunera, llegadas en coherencia con las políticas posrevolucionarias - cito a la autora - de "reacomodar a los campesinos sin tierra, aumentar las producciones agrícola y ganadera y promover la creación de nuevos centros de población para evitar conflictos limítrofes con Guatemala". ${ }^{10}$ En el relato actual, las vicisitudes pasadas por los colonos se convierten así en logro del objetivo de las políticas colonizadoras: "una nueva cultura nacía. El Norte y el Sur se fusionaban, se homogeneizaban" (Quiriarte, 2009: 13 y 49). No es un detalle menor que las nuevas colonias rebautizaran espacios que tenían nombres reconocidos localmente, con otros de personajes de significación nacional o de referencia a otras localidades de la República - Nuevo Coahuila, Estado de México, Venustiano Carranza, Lic.
Miguel Alemán, Monclova, Benito Juárez, etcétera-.

Una dinámica muy parecida es la analizada por Ubaldo Dzib para la localidad de Chicbul, también en la zona maderera campechana, en la que los colonos llegados desde Baja California con ayuda gubernamental en 1965, llevaron como parte de su bagaje cultural la celebración de la independencia nacional: "Con el rito de reproducción en Chicbul del simbolismo nacional basado en héroes oficiales, los colonos incorporaban una localidad rural, anteriormente aislada en la selva, a la nación como comunidad imaginada". (Dzib, 2004: 36-37).

Un proceso similar de nacionalización por parte de un Estado se encuentra, por ejemplo, en poblaciones fronterizas de la Amazonía cauchera (Arruda, 2009), donde los llamados "antiguos" moradores de la frontera construyen su identidad con base en referentes locales, llamados "amazónicos", frente a los inmigrantes que continuamente llegan y que construyen el derecho al uso y explotación de las tierras en función de referentes nacionales, identificados como peruanos, bolivianos, etcétera. Los “antiguos" son considerados no nacionalizadores por no esgrimir claramente fidelidades a la nación en la dinámica transfronteriza que los define.

\section{El consabido recurso a la frontera-frente para nacionalizar la frontera-límite}

Con este rápido recorrido por la historia de un fragmento en la construcción mexicana de su "frontera sur", parece evidente la permanencia del constructo ideológico liberal del "vacío territorial" — heredado de sus antecesores coloniales-, reiteradamente utilizado para justificar nuevos ciclos de colonización que desconozcan los anteriores. Dicho constructo se cimentaba en la negación de la existencia de población en una región determinada o, en caso de reconocerla, en resaltar la ausencia de control del aparato estatal sobre ella, en la ausencia de legalidad reconocida por el Gobierno de turno. Ello justificaba la entrada de grupos promotores del progreso y la inclusión subalterna de los pobladores locales a dicho proyecto de modernización, además de que permitía el control de ese territorio por parte del Estado. Tierra sin gente, 
no cultivada, sin propiedad reconocida legalmente y de inmensa riqueza — esperando ser explotada - son los constructos ideológicos que alimentaron el imaginario social sobre las fronteras internas de los Estados en construcción de su propia territorialidad. En ese constructo basan su planteamiento varios estudiosos de la ocupación territorial en el sur mexicano (Skerritt, 1998; Macías y Bracamonte en Macías, 2004; González, 2008; Torras, 2012a; Villafuerte y García, 2014; Cunin, 2014). La investigación sobre el proceso de poblamiento de Quintana Roo realizada por Elisabeth Cunin, por ejemplo, demuestra cómo a inicios del siglo XX la administración mexicana consideraba la región como un desierto demográfico en el cual los pocos individuos presentes -indígenas, negros, prisioneros - no contaban (Cunin, 2014: 35).

Es precisamente la ideología de la colonización, basada en atribuirle a un espacio determinado las características de despoblado y rico en recursos naturales, la que articula la noción de colonialismo a la de colonización y, asimismo, genera el concepto de frontera-frente. Como nos recuerda Luis Aboites en su escrito sobre la obra de Moisés González Navarro, "la colonización siempre tuvo como supuestos ideas sobre dicha combinación: población escasa, mal distribuida y de deficiente calidad, y un territorio dotado de inmensas riquezas naturales" (Aboites, 1992: 84). No obstante, Aboites hace notar, discrepando de González Navarro, la continuidad de esa construcción ideológica decimonónica hasta el cardenismo, sustentada a menudo en los temores por la soberanía territorial. Salvando las notorias diferencias entre los programas de poblamiento, permanece la noción de "vacío territorial" recreada como mito justificador cada vez que hay un nuevo grupo que pretenda la ocupación de ese espacio.

La frontera como frente de expansión, conformada a partir de ciclos sobrepuestos de colonización con participación diferenciada del Estado, produce fronteras culturales dentro de las poblaciones y los distingue en cuanto a su identidad territorial. Para los "nativos", ésta se encuentra asociada con el espacio local; para los "norteños" pasa por la identidad nacional. Y esos referentes distintivos se traducen en la experiencia cotidiana al ser activados políticamente, lo que crea exclusión y desigualdad ciudadana. Los "norteños" pueden construir su identidad en un discurso fundacional gracias a sus referentes nacionales consolidados con anterioridad y que coinciden con las filiaciones partidarias de políticos estatales, aunque ello implique arrebatar a los "nativos" su legitimidad construida con base en los derechos adquiridos con el tiempo sobre un espacio local distanciado - cuanto menos - del Estado. La disputa es simbólica, es por la legitimidad.

Lo anterior implica políticas de memoria basadas en la desmemoria del ciclo anterior, con el propósito de romper líneas de continuidad histórica creadoras de sentidos de pertenencia considerados "desafectos" al poder centralizador. De ahí la necesidad de los gobiernos centrales de generar dispositivos de nacionalización de sus extremos territoriales, entendida dicha nacionalización en la lógica de rehacer lealtades ante la fragilidad de una sociedad marginalizada. La misma precariedad generada por los modelos de colonización limita el ejercicio de la ciudadanía de quienes habitan esas eternamente "tierras prometidas" a las siempre quebradizas relaciones clientelares afectas a los gobiernos de turno.

Nuevas oleadas, como la mencionada en un inicio de los "michoacanos", resignifican las fronteras culturales, de modo que los "norteños" podrían pasar a ser "nativos" para los recién llegados. Esta realidad choca con la lógica estatal, que necesita fijar sentidos de pertenencia nacional en una frontera pretendidamente inmutable, pues para todo Estado-nación es prioritario que, efectivamente, la frontera sea frontera-límite y marque su soberanía frente al país vecino (Castillo et al., 2006: 16-17). Pero, sobre todo, que nacionalice sus periferias según los patrones culturales e identitarios legitimados por el poder central y con filiaciones políticas controladas desde el centro. De hecho, parecería que el meollo de la cuestión es tratar de entender cómo se demarcó la frontera-límite a partir de las lógicas de la frontera-frente.

En este sentido, resulta particularmente sugerente la reflexión teórica que nos ofrece Andrés Fábregas 
en su texto sobre fronteras y colonialismo (2012), al cuestionar el rechazo que manifiesta Turner de reconocer en su tesis el papel del Estado en la construcción de la frontera. Es evidente, como insiste el antropólogo mexicano, que los Estados-nación se formaron a partir de su expansión hacia esos espacios concebidos como vacíos, aún más si son limítrofes; en nuestro caso, hacia las selvas del sureste. Valga decir que las políticas agrarias porfirianas de adjudicación de tierras y poblamiento a través de las cuales el Estado delegaba a grandes propietarios nacionales y extranjeros sus funciones de territorialización - como en el caso referido de Ana Niévez de Repetto-, éstos se convirtieron en agentes de la colonización gracias a las facilidades y privilegios otorgados por el Estado, más allá de su propia iniciativa individual. Igual pasó con sus antecesores, como Juan de Dios Mucel o Enrique Pauling, pioneros en este ejercicio gracias a las ventajas que el Estado les daba a través de la legislación liberal de terrenos baldíos (Torras, 2012b). Efectivamente, no podemos utilizar la noción turneriana, tan ampliamente difundida desde que saliera a la luz pública en 1893, como herramienta de análisis sin incorporar el factor señalado por Fábregas.

Ahora bien, donde quisiera poner énfasis en esta ocasión es en la noción de Turner como reflejo de la ideología de su tiempo y, por su gran influencia, como constructor de la idea implícita en el concepto mismo de asociar colonización a colonialismo. Como bien afirma Ramón González Ponciano, la concepción liberal que ampara el proceso civilizatorio en México durante todo el siglo XIX y buena parte del XX refleja la influencia más política que conceptual de la noción turneriana de frontera (González, 2008: 82).

La lógica de expansión bajo la premisa del "vacío territorial", aunque variando la elección del tipo de colono deseado, ha sobrevivido al paso del tiempo, y sigue reinventándose, lo que dificulta una apropiación sólida del territorio por parte de sus pobladores y, precisamente por ello, requiere de mayores dispositivos de nacionalización.

Construir una historia y una memoria que den cierta estabilidad a la autodefinición identitaria a partir de la diferencia con el otro grupo; marcar una frontera fuerte que permanezca a pesar de los cambios culturales internos inherentes a todo grupo social a través de la ideación del pasado —-memoria históricaconformada con referentes patrimoniales, nos recuerda que la memoria no es sólo representación sino sobre todo construcción constituyente. Y la territorialidad, uno de los marcos sociales fundamentales para la construcción de memoria colectiva, memoria que necesita continuamente ser reactivada. Es en los lugares marcados por las migraciones, por la inestabilidad de asentamiento, por el desarraigo, donde se hace más imperiosa la necesidad de organización espacial de la memoria colectiva. Allí donde anclar los recuerdos, donde recrear materialmente centros de continuidad social para garantizar la lealtad de sus ocupantes al Estado-nación.

Es por ello que, más allá de ser el caleidoscopio de las "culturas híbridas", las fronteras son lugares de densificación de los contactos interculturales entre culturas desiguales. La identificación de "colono" expresada por los pobladores se va moviendo en función de las nuevas oleadas de migrantes de otros estados mexicanos que llegan de tal manera que, el que fuera colono poco tiempo atrás, se considere "autóctono" o "nativo" frente a los recién llegados en un proceso acelerado de apropiación del territorio que lo oponga al extraño, pues siente amenazada su hegemonía cultural.

Y es allí, en las franjas fronterizas, donde el Estado mexicano invierte más recursos simbólicos para consolidar su hegemonía produciendo lo que Gilberto Giménez llama - y encontramos en Candelaria - "el lugar de las identidades exasperadas en confrontación recíproca, donde las dominantes luchan por mantener su hegemonía, en tanto que las dominadas lo hacen para lograr su reconocimiento social" (Giménez, 2009: 24 25), siendo que el Estado nunca cesa de descomponer, recomponer y transformar el movimiento productor de territorio o de regular el discurso que fije su sentido unitario y homogeneizador. Sobre todo, en esas áreas donde los procesos de fronterización impulsados tienen como objetivo su incorporación subalterna, dentro de un sistema capitalista basado en la desigualdad territorial, 
máxime si son áreas acotadas por una frontera-límite con otro Estado nacional cuya población - tanto de un lado como del otro de la línea- viven con dinámicas transfronterizas de larga data.

\section{Notas}

${ }^{1}$ El presente artículo es uno de los resultados del proyecto Historias de Migración en Campeche, investigación realizada gracias al Programa UNAM-DGAPA-PAPIIT IA400214-2.

2 Casa de la Cultura Jurídica de Campeche (CCJC), Fondo Baldíos y Archivo General del Estado de Campeche (AGEC), Colección Raúl Novelo Bombat, Municipio Carmen.

${ }^{3}$ Cabe distinguir dos momentos en el largo y contestado proceso de demarcación del límite entre Guatemala y México: uno que culminó con el Tratado de Límites del 27 de septiembre de 1882, firmadoen la ciudad de México y que avanzó en la delimitación entre los departamentos guatemaltecos de San Marcos y Huehuetenango y parte del estado mexicano de Chiapas; el otro, con el llamado "arreglo final" de abril de 1895 que pretendía zanjar las diferencias en torno al límite entre el departamento guatemalteco del Petén y los estados de Tabasco y Campeche y parte del de Chiapas del lado mexicano. El Tratado de 1882 estableció la formación de dos Comisiones de Límites - una de Guatemala y otra de México - encargadas de las operaciones para hacer efectivos los límites acordados. (Valdez, 2008). Sobre ese complicado proceso, se recomienda Castillo et al., 2006, Valdez, 2006 y De Vos, 1988.

4 AGEC, Colección Raúl Novelo Bombat, Municipio Carmen, caja 23, exp. 26-892, f. 29.

${ }^{5} 44094$ hectáreas son 440.94 kilómetros cuadrados; 2500 hectáreas son 25 kilómetros cuadrados.

6 Registro Parroquial Nuestra Señora del Carmen (RPNSC), Libro $11^{\circ}$ de Bautismos, años 1834-1843, f. 165.

${ }^{7}$ Archivo General Agrario (AGA), Campeche, Carmen, Candelaria, exp. 6559 leg. 1, 207 fs.

${ }^{8}$ Fragmentos extraídos del documental El desierto quedó atrás, guionista Emilio Carballido, 1964 (Candelaria. Imágenes, 2004: 27 y 25).
${ }^{9}$ Extraído del documental El desierto quedó atrás, guionista Emilio Carballido, 1964 (Candelaria. Imágenes, 2004: 21).

${ }^{10}$ En 1963 se adicionó el artículo 58 al Código Agrario. En él se estipulaba que los terrenos nacionales se destinarían a constituir y ampliar ejidos o a establecer nuevos centros de población ejidal, prohibiéndose específicamente la colonización privada. (Ruiz Massieu, 1988: 90). Aunque no tengo constancia de ninguna disposición legal al efecto, es evidente la intención de poblar el límite con Guatemala a partir de los nuevos asentamientos ejidales que son autorizados a partir de 1963 (ver expedientes del AGA).

\section{Referencias bibliográficas}

Arruda, Rinaldo et al. (2009). Historias y memorias de las tres fronteras. Brasil, Perú y Bolivia. Cuzco, Perú: Grupo Frontera.

Aboites, Luis (1992). "La colonización de Moisés González Navarro”. En Shulamit Goldsmit y Guillermo Zermeño (coords.), La responsabilidad del historiador. Homenaje a Moisés González Navarro. México: Universidad Iberoamericana.

"Candelaria. Imágenes" (2004). En Blanco y Negro, núm. 6, diciembre, pp. 1-28.

Castillo, Miguel Ángel, Mónica Toussaint Ribot y Mario Vázquez Olivera (2006). Espacios diversos, historia en común. México, Guatemala y Belice: la construcción de una frontera. México: Secretaría de Relaciones Exteriores.

Cunin, Elisabeth (2014). Administrar los extranjeros: raza, mestizaje, nación. Migraciones afrobeliceñas en el territorio de Quintana Roo, 1902-1940. México: CIESAS, IRD.

De Vos, Jan (1988). Oro verde: La conquista de la Selva Lacandona por los madereros tabasqueños, 1822-1949. México: FCE, Instituto de Cultura de Tabasco.

Del Carpio Penagos, Carlos Uriel (2004). "La colonización de la frontera Chimalapa. Lucha por la apropiación territorial”. En Espiral, vol. X, núm. 29, enero-abril, pp. 161-197.

Dzib, Ubaldo (2004). "Diversidad cultural y poder en la formación del ejido Chicbul, Carmen, Campeche”. En Estudios Agrarios, núm. 10, pp. 36-37. 
Fábregas Puig, Andrés (2012). "Fronteras y colonialismo: una reflexión desde la frontera México-Guatemala". En Journal of Latin American and Caribbean Anthropology, vol. 17, núm. 1, pp. 6-23.

Fábregas Puig, Andrés y Ramón González Ponciano (2014). "The Mexico-Guatemala, Guatemala-Mexico Border: 1983-2013”. En Frontera Norte, vol. 26, núm. especial 3, pp. 7-35.

Giménez, Gilberto (2009). "Cultura, identidad y memoria. Materiales para una sociología de los procesos culturales en las franjas fronterizas". En Frontera Norte, vol. 21, núm. 41, enero-junio, pp. 7-32.

González Ponciano, Ramón (2008). "De Frederick Jackson Turner a Samuel P. Huntington: xoc de civilitzacions i la gent de la frontera". En Revista d'Etnologia de Catalunya, núm. 33, pp. 82-93.

Macías Zapata, Gabriel Aarón (coord.) (2004). El vacío imaginario. Geopolítica de la ocupación territorial en el Caribe oriental mexicano. México: CIESAS, Congreso del Estado de Quintana Roo.

Quiriarte Rodríguez, Maritoña(2009).Chan-colona.Imagen del pasado, orgullo del presente. Campeche: Gobierno del Estado de Campeche.

Revel-Mouroz, Jean (1980). Aprovechamiento y colonización del trópico húmedo mexicano. México: Fondo de Cultura Económica.

Ruiz Massieu, Mario (1988). "Temas de derecho agrario mexicano". En Estudios Doctrinales, núm. 46. México: Instituto de Investigaciones Jurídicas-UNAM.

Sierra, Carlos Justo (1998). Breve historia de Campeche. México: Fondo de Cultura Económica.

Skerritt, David (1998). "La formación de las élites en Veracruz: un espacio vacío de la tierra caliente, 1833-1960”. En María Eugenia Romero Ibarra y
Pablo Serrano Álvarez (coords.), Regiones y expansión capitalistaen México duranteel siglo XIX. México: UNAM/ Universidad de Colima.

Taracena Arriola, Arturo y Miguel Pinkus Rendón (eds.) (2010), Cartografía histórica de la península de Yucatán. Mérida, Yucatán: UNAM, CEPHCIS [formato CD ROM].

Torras Conangla, Rosa (2012a). La tierra firme de enfrente. La colonización campechana sobre la Región de Los Ríos (siglo XIX). Mérida, Yucatán: CEPHCIS-UNAM

Torras Conangla, Rosa (2012b). "El impulso colonizador de la frontera terrestre de la península de Yucatán (siglo XIX)". En Península, vol. VI, núm. 2, otoño, pp. 103-117.

Torras Conangla, Rosa (2013). “iDiversas visiones de nación?: disputas territoriales en la frontera sur de la península de Yucatán”. En Arturo Taracena, Carolina Depetris y Adam Sellen (eds.), Miradas regionales. Las regiones y la idea de nación en América Latina, siglos XIX y XX. Mérida, Yucatán: CEPHCIS-UNAM, pp. 83-102.

Turner, Frederick Jackson (1987). "El significado de la frontera americana (1893)". En Secuencia, enero-abril, pp. 186-207.

Valdez Gordillo, Mario (2006). Desencuentro y encuentro de fronteras: el Petén guatemalteco y el sureste mexicano, Tuxtla Gutiérrez, Chiapas: UNICACH/UNICH.

Valdez Gordillo, Mario (2008). "Chiapas: de la 'guerra de los mapas' de 1895 a las regiones de frontera. Un análisis desde la perspectiva de la geografía política y la geografía histórica". En Takwá, núm. 14, otoño, pp. 59-87.

Villafuerte Solís, Daniel y María del Carmen García Aguilar (2014). "Tres ciclos migratorios en Chiapas: interno, regional e internacional”. En Migración y Desarrollo, núm. 22, pp. 3-37. 


\section{Mapa 1. Plano de San Pedro y anexos, 1907}

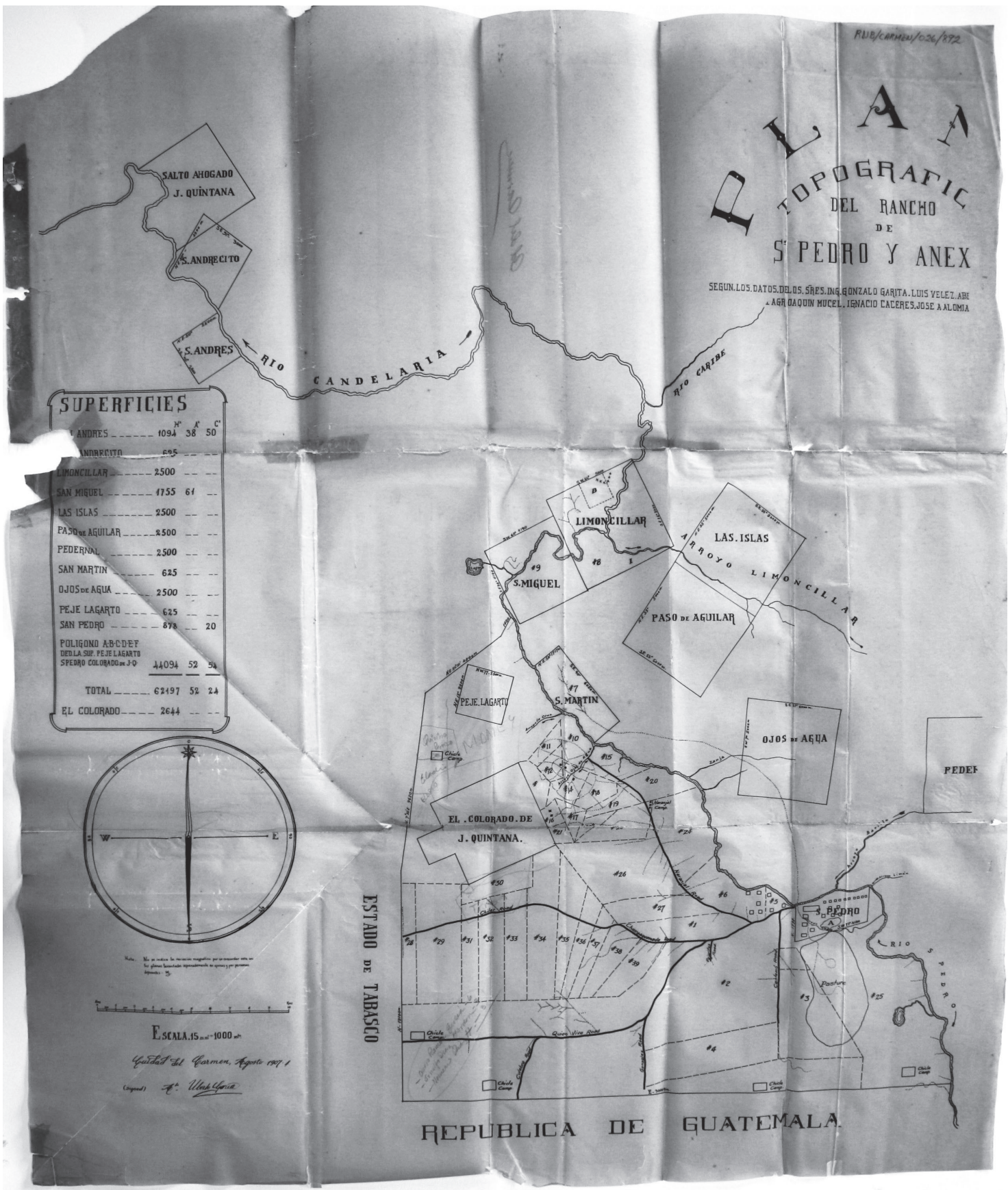

Fuente: AGEC, Colección Raúl Novelo Bombat, Municipio Carmen, caja 23, exp. 26-892. 